\title{
Hepatic Impairment
}

Yue Kang ${ }^{1}$, Fengyan $\mathrm{Xu}^{2}$, Kun Wang ${ }^{2}$, Jing $\mathrm{Zhang}^{1}$, Xiaojie $\mathrm{Wu}^{1}$, Jufang $\mathrm{Wu}^{1}$,

4 Guoying $\mathrm{Cao}^{1}$, Jicheng $\mathrm{Yu}^{1}$, Beining Guo ${ }^{1}$, Yuancheng $\mathrm{Chen}^{1}$, Yingyuan Zhang ${ }^{1}$

5 1. Institute of Antibiotics, Huashan Hosptial, Fudan University, Shanghai, China

6 2. Certara Strategic Consulting China, shanghai, 200122, China

\section{Correspondence:}

8 Professor Dr. Jing Zhang

$9 \quad$ Institute of Antibiotic

Huashan Hosptial, Fudan University

Shanghai, China, 200040

Tel +8613816357098

E-mail: $13816357098 @ 163 . c o m$

Running title: Morinidazole Population Pharmacokinetics Study

Keywords: morinidazole; population Pharmacokinetics; liver dysfunction; renal dysfunction; dosage adjustment

\section{Abstract}

Objective Morinidazole is a novel third generation 5-nitroimidazole antimicrobial drug which has demonstrated substantial antibacterial activity against clinical isolates of anaerobe. The aim of this study was to build population pharmacokinetic (PPK) model of morinidazole among patients with hepatic impairment and to provide dosage adjustment strategy for morinidazole in patients with hepatic impairment and/or renal 
dysfunction.

Methods The nonlinear mixed effects modeling tool NONMEM (version7.3, ICON Development Solutions) was used to develop the PPK model of morinidazole.

Results One-compartment model was conducted to establish the morinidazole PPK model. Disease condition was the significant covariate for CL and weight was the significant covariate for $\mathrm{V}$. The $\mathrm{AUC}_{0-\infty}$ was $120.44 \pm 37.05(79.25-207.20) \mu \mathrm{g} \times \mathrm{h} / \mathrm{mL}$ in hepatic impairment group and was 79.46 $\pm 23.71(42.94-116.75) \mu \mathrm{g} \times \mathrm{h} / \mathrm{mL}$ in control group. The $\mathrm{AUC}_{0-\infty}$ was $164.9 \pm 44.8 \mu \mathrm{g} \times \mathrm{h} / \mathrm{mL}$ and $77.2 \pm 23.1 \mu \mathrm{g} \times \mathrm{h} / \mathrm{mLin}$ in the 3 subjects with both hepatic impairment and mild renal impairment and in the 3 matched healthy subjects, respectively.

Conclusion It is not necessary to adjust morinidazole dosage for patients with moderate hepatic impairment without confirmed renal dysfunction. For patient with moderate hepatic and mild renal impairment, morinidazole regimen should be considered as 500mg every 24 hours. When used in patients with moderate/severe hepatic impairment combined with renal dysfunction, both dosage and interval adjustment of morinidazole should be considered.

\section{Introduction}

Morinidazole is a novel third generation 5-nitroimidazole antimicrobial drug which has demonstrated substantial antibacterial activity against clinical isolates of anaerobe including gram negative Sporeless bacterium and gram-positive coccus based on the result of pharmacodynamics study in vitro. The antibacterial activity of morinidazole against Bacteroides fragilis, Veillonella and Clostridium perfringens is 
comparable to that of ornidazole, which is 2 to 8 times stronger than that of metronidazole and tinidazole. The antibacterial activity of morinidazole against Bacteroides distasonis and Bacteroides ovatus is comparable to that of ornidazole, which is 2 to 8 times stronger than that of metronidazole and tinidazole as well $(1,2)$. Morinidazole and Sodium Chloride Injection was approved by CFDA in February 2014 for the treatment of pelvic inflammatory disease caused by Peptostreptococcus, Bacteroides fragilis, Veillonella and Bacteroides distasonis, suppurative appendicitis and gangrenous appendicitis caused by anaerobes(3).

Morinidazole showed a positively correlated relationship between dosage and AUC $_{0-\mathrm{t}}$ as well as $\mathrm{C}_{\text {max }}$. The $\mathrm{V}_{\text {ss }}$ of morinidazole was $1209 \pm 158 \mathrm{~mL} / \mathrm{kg}$ after infusion at $16 \mathrm{mg} / \mathrm{kg}$ for $2 \mathrm{~h}$. The human plasma protein binding rate of morinidazole was 22.1 to $27.2 \%$. Morinidazole was widely distributed in tissues and body fluids. Morinidazole was mainly metabolized by glucuronidation (mediated by UGT1A9 enzyme) and sulfation rather than CYP450 in human. It took $36 \mathrm{~h}$ for $70 \%$ morinidazole to excrete as unchanged drug and phase II metabolites via renal pathway in healthy subjects(3).

Phase I to phase III clinical trials had been completed before morinidazole launching. Our team had finished the pharmacokinetics study of morinidazole in moderate hepatic impaired subjects in 2010, the results showed the $\mathrm{AUC}_{0-\infty}$ of hepatic impaired subjects and healthy subjects is $116.3 \pm 41.8 \mu \mathrm{g} \times \mathrm{h} / \mathrm{mL}$ and $77.2 \pm 25.3$ $\mu \mathrm{g} \times \mathrm{h} / \mathrm{mL}$, respectively. The $\mathrm{AUC}_{0-\infty}$ of 3 hepatic impaired subjects with mild renal function impaired was $166.7 \pm 52.1 \mu \mathrm{g} \times \mathrm{h} / \mathrm{mL}$. The metabolism rate of a nitrogen-oxide 
(N-oxide), M2, was low (2). Meanwhile, the pharmacokinetics study of morinidazole among severe renal function impaired subjects had been conducted. The AUC of severe renal function impaired subjects was 1.4 times higher than that of healthy subjects(4). However, non-compartment model analysis which published before cannot assess the impact of patient physiology and pathology condition on pharmacokinetics(PK) parameters. Hence, compartment model was performed in order to assess the impact of variables on AUC in this study. In clinical practice, some patients who experiencing infections have complications of liver functions impairment and/or renal function impairment, while some elderly patients have liver function impaired with physiologically decreased glomerular filtration rate. Moreover, the PK study among hepatic function impaired patients used creatinine clearance rate (CCr) to assess the renal function of subjects. The guideline of KDIGO recommends assessing renal function by estimated glomerular filtration rate (eGFR)(5). The value is always not equal between $\mathrm{CCr}$ and eGFR(6), thus the renal function was reassessed in this study. The aim of this study was to build the PPK model of morinidazole among liver dysfunction patients and explore the covariate in hepatic impairment patient as well as to compare the PK parameter changes in patients with liver dysfunction combined with renal dysfunction by model simulation in order to provide the dosage adjustment strategy of morinidazole in the special populations and to guide the rational use.

\section{Methods}

\section{Data of Study for PPK Modeling}


Data from the PK study of morinidazole among patients with hepatic function impairment (Study No. ChiCTR1800015771, approved by HIRB of Huashan hospital, Fudan University on $6^{\text {th }}$ November 2009) (2), including demographic characteristics, laboratory test results and plasma concentrations were used for PPK analysis. The study was an open-label, single dose, parallel control study in which 12 subjects were enrolled in the moderate liver function impaired group and the healthy controlled group, respectively. Single dose of 500mg morinidazole and sodium chloride injection $(500 \mathrm{mg} / 100 \mathrm{ml})$ was administrated via intravenous infusion for $45 \mathrm{~min}$. All the blood samples were collected from pre-dosing to within $48 \mathrm{~h}$ after infusion.

\section{Subjects}

Individuals with moderate (Child-Pugh class B) hepatic impairment caused by hepatitis B induced cirrhosis were enrolled in hepatic impaired group. The healthy control subjects were matched based on the age ( \pm 5 years old), gender and weight $( \pm 15 \%)$ of liver function impaired subjects. CKD-EPI equation (2009) was used to reevaluate the eGFR of the subjects(7). Moreover, model for end-stage liver disease (MELD) and Albumin-Bilirubin (ALBI) score were performed to reassess the liver function of subjects from liver function impaired group. Demographic characteristics were shown in Table 1

\section{Study Design}

Plasma samples were collected prior to administration of morinidazole, 22.5min after start of the infusion and at $0 \mathrm{~h}, 0.25,1,2,4,6,8,12,24,36,48 \mathrm{~h}$ after the end of 
111 infusion. Liquid chromatography-tandem mass spectrometry (LC-MS/MS) was

112 performed to determine the concentration of unchanged morinidazole.

\section{Safety Assessment}

Blood samples were collected to assess the liver and renal function in screening period, on the dosing day, as well as at $24 \mathrm{~h}$ and $48 \mathrm{~h}$ after administration of morinidazole. The safety assessment included results analysis of clinical manifestations, vital signs, physical examination, laboratory tests and 12-lead electrocardiogram (ECG).

\section{Data description}

A total of 336 concentrations samples from 24 subjects were used to establish the

PPK model. analysis and parameter rationalities. Covariate analysis was conducted after the

\section{PPK Modeling Building}

\section{Basic Modeling Building}

Tow-compartment and one-compartment model was evaluated to describe the pharmacokinetics of morinidazole indications. A modeling analysis was conducted using the nonlinear mixed effects modeling tool NONMEM (version7.3, ICON Development Solutions).

\section{Covariate analysis}

The model was based on the first-order conditional estimation (FOCE) method with $\eta-\varepsilon$ interaction. Model selection was based on likelihood ratio tests, residual selection of the base model. Scatter plots of parameter estimates from the selected 
133

base model and potential covariates (including: disease condition (moderate hepatic impairment or health), gender, height, weight, body mass index(BMI), alanine aminotransferase(ALT), aspartate transaminase(AST), ascites, total bilirubin(TB), Child-Pugh score and estimated glomerular filtration rate (eGFR) were plotted to explore covariate-parameter relationships. The Stepwise Covariate Model (SCM) module in Perl-speaks-NONMEM software (version 3.4.2, Uppsala University, Sweden) was then used for covariate screening and identification.

Covariate relationships as linear function, exponential function and power function were assessed for continuous covariates, and a stepwise approach was used to evaluate covariate effects. The statistical criteria for a covariate to be incorporated in the model were a decrease of $>3.84$ in the OFV $\left(p=0.05, \chi^{2}\right.$ distribution with one degree of freedom) in the forward step and an increase of $<6.63$ in the OFV ( $p=0.01$, $\chi 2$ distribution with one degree of freedom) in the backward step. A decrease in objective function value $(\mathrm{OFV})>6.63$ was considered statistically significant.

\section{Model assessment and validation}

The goodness-of-fit was evaluated by comparing the following graphs both in base model and in final model: observed concentrations versus population predictions (DV vs PRED), observed concentrations versus individual predictions (DV vs IPRE), conditional weighted residuals (CWRES) versus time, and CWRES vs PRED.

A bootstrap resampling technique was used for the model validation. The advantage is that calculation of certain statistics with a nonparametric bootstrap method does not depend on the assumption of sample distribution. The basic idea is to 
155

156

157

158

159

160

161

162

163

164

165

use the Monte Carlo method repeated sampling with replacement in the sample, thus forming a self-sampling. Once the self-sampling reaches a certain frequency, it forms a statistical distribution, and the original sample statistics can then be estimated with a semi-empirical method. Visual predictive check (VPC) was used to graphically assess the appropriateness of the compartment model because of the importance of the ability of the model to simulate data similar to the original data. The concentration profiles were simulated 1000 times and compared with observed data to evaluate the predictive performance of the model.

\section{Post-hoc analysis and Simulations}

The $\mathrm{AUC}_{0-24}$ of individuals and the change of $\mathrm{AUC}_{0-24}$ based on Child-Pugh score was simulated by PK parameters and Intra- and inter- individual variation based on the final model

\section{Individual Parameters}

Descriptive statistical analysis was used to analyze the PK parameters of 24 subjects which calculated by population pharmacokinetics method by NONMEM via SPSS (Version 17.0). Meanwhile, the hepatic function of the 12 liver impaired subjects was reassessed by MELD and ALBI score to observe the correlation between

MELD /ALBI score and AUC of morinidazole.

\section{Correlation Analysis Between Covariate and Morinidazole $\mathrm{AUC}_{0-24}$}

Spearman's correlation was conducted by SPSS (Version 17.0) to analyze the correlation between the covariates and morinidazole $\mathrm{AUC}_{0-24}$. The covariates included ALT, AST, GGT, TB, ABL, prolongation of the prothrombin time and eGFR. 


\section{Results}

\section{PPK Modeling Analysis}

\section{Basic Model}

The plasma concentration of 24 subjects was used to build the model (Figure 1).

The Child-Pugh score of 12 moderate hepatic impaired subjects caused by chronic virus hepatitis induced cirrhosis was from 7 to 9 (average was 8). Both one-compartment and two-compartment model were performed to establish the basic model. One-compartment model fit the data more precisely than two-compartment model and thus was selected as the basic model. The objective formulation value $(\mathrm{OFV})$ was 4502.814 . The parameters of PPK included CL $(5.32 \mathrm{~L} / \mathrm{h})$ and $\mathrm{V}_{\mathrm{c}}(50.5 \mathrm{~L})$ of morinidazole. The inter-individuals variation was well descripted by the index model.

\section{Covariate Analysis}

Scatter plots of parameter estimates from the selected basic model and potential covariates showed that height, weight, disease condition, hepatic encephalopathy, prolongation of the prothrombin time and ALB $(\mathrm{P}<0.01)$ as well as moderate hepatic impairment combined with eGFR $\leqslant 90 \mathrm{ml} / \mathrm{min} / 1.73 \mathrm{~m}^{2}$, ascites, TB and Child-Pugh score $(0.01<\mathrm{P}<0.05)$ were the potential covariates. As a result, disease condition, ALB, Child-Pugh score, ascites, TB and eGFR were selected as potential covariates for CL. Weight was chose as the potential covariate for V. It was showed that disease condition was the significant covariate for CL and weight was the significant covariate for $\mathrm{V}$ via forward selection and backward deletion. The covariate equation 
199

200

201

202

203

204

was as the following:

$$
\begin{aligned}
& C L=T V C L * C O V_{\text {CL_pat }} \\
& \text { COV }_{C L_{-} \text {pat }}=\left\{\begin{array}{lll}
1 & & \text { if pat }=\text { volunteer } \\
& 1+\theta_{C L_{-} \text {pat }}=1+0.526=1.526 & \text { if pat }=\text { patient }
\end{array}\right. \\
& V=T V V *\left(\frac{w e i g h t}{70}\right)
\end{aligned}
$$

$\theta_{C L \_p a t}$ is the changed value of dichotomy covariate of $\mathrm{COV}_{\mathrm{cl}}$ in moderate hepatic impairment patients.

\section{Modeling evaluation and validation}

The population parameter estimates of the final model for CL and V were illustrated in Table 2. The population estimate values (RSE\%) were 4.32 L/h (8.30\%) for $\mathrm{CL}$ and $55.5 \mathrm{~L}(4.80 \%)$ for $\mathrm{V}$. Incorporation of patient status and weight as covariate effects on CL and V decreased the OFV from 4502.814 to 4483.082.

The GOF figure of model evaluation showed that both population and individual predictions were consistent with observation value and the final model fit better than the basic model. The figure of Individual prediction vs. observation, Population prediction vs. observation, Conditional weighted residual vs population prediction and Conditional weighted residual vs time was in Figure 2

In Figure 2, the red line in (A) and (B) represented regression line, respectively, whereas in (C) and (D) were the position where conditional weighted residual equal 0.

The final model was validated by nonparametric bootstrap. The results demonstrated a complete overlap of the $95 \%$ confidence interval of parameter estimates with the ranges of the $2.5^{\text {th }}$ to $97.5^{\text {th }}$ percentiles, indicating that the final 
221

222

model was robust (Table 2). The final model demonstrated strong stability, with 1000 bootstrap runs fitting successfully, and bootstrap estimates very similar to the population estimates.

Figure 3 showed the results of VPC using 1000 monte carlo simulations. The observed concentration was included in the range of confidence intervals and the median and 95\% confidence interval lines were located near the middle area of the 1000 results, suggesting the sufficiency of the predictive power of the model.

Open circles represented observed concentrations. The solid line and the dashed line represented the median and the $95 \%$ CI of observation, respectively. The middle red shadow areas represented the $95 \%$ confidence intervals of median for the results of 1000 times simulation of final model and the blue shadow areas represented the $95 \%$ confidence intervals of the 2.5th and 97.5th percentiles of the results of 1000 times simulation of pharmacokinetic final model.

\section{PK Parameters of Individuals}

The $\mathrm{AUC}_{0-\infty}$ was $120.44 \pm 37.05(79.25-207.20) \mu \mathrm{g} \times \mathrm{h} / \mathrm{mL}$ in hepatic impairment group and was $79.46 \pm 23.71(42.94-116.75) \mu \mathrm{g} \times \mathrm{h} / \mathrm{mL}$ in control group. Other PK parameters were listed in table 3 . There were 3 subjects from hepatic impairment group combined with eGFR $\leqslant 90 \mathrm{ml} / \mathrm{min} / 1.73 \mathrm{~m}^{2}$. Although the eGFR of one subjects was $90 \mathrm{ml} / \mathrm{min} / 1.73 \mathrm{~m}^{2}$, the urine routine test revealed weakly positive urine protein and occult blood. Therefore, the subject was diagnosed with mild renal function impairment. The $\mathrm{AUC}_{0-\infty}, \mathrm{C}_{\max }, \mathrm{CL}, \mathrm{V}$ and $\mathrm{t}_{1 / 2}$ of the three subjects were $164.9 \pm 44.8$ 
(range was from 117.9 to 207.2 ) $\mu \mathrm{g} \times \mathrm{h} / \mathrm{mL}, \quad 16.53 \pm 3.62 \mu \mathrm{g} / \mathrm{mL}, \quad 3.2 \pm 0.94 \mathrm{~L} / \mathrm{h}$,

the 3 matched healthy subjects were $77.2 \pm 23.1$ (range was from 54.9 to 101.0)

The correlation between $\mathrm{AUC}_{0-24}$ and Child-Pugh score was showed in Figure 4.

\section{Spearman's rank correlation coefficient analysis}

Spearman's rank correlation coefficient was used to analyze the correlation

\section{Discussion}

To our knowledge, this study was the first study to explore the one-compartment model with first-order elimination was optimal for pharmacokinetic data modeling. was the significant covariate for V based on the result of this PPK study. 
China(8). Hepatitis B was the cause of hepatic impairment of all the 12 subjects.

Child-Pugh score is recommended by FDA to assess the liver function in the PK study of hepatic impaired population(9). Besides Child-Pugh score, MELD score and ALBI Grade are conducted to assess the liver function in clinical practice as well. Child-Pugh is widely used with the index of the synthetic function (ALB and PT) and the elimination function (TB) of liver. It is known that renal function, affecting the PK of morinidazole, is also an important index to predict the prognosis of hepatic function whilst not included in Child-Pugh score. (10) Therefore, the other two score were used to reassess the liver function of the subjects in this study.

MELD score uses serum creatinine, international normalized ratio (INR) and TB as indexes, which reflect the renal function, synthetic and elimination function of liver. The equation of MELD is $3.78 \times \operatorname{Ln}(\mathrm{TB} \mu \mathrm{mol} / \mathrm{L})+11.2 \times \operatorname{Ln}(\mathrm{INR})+9.57 \times$ $\mathrm{Ln}($ creatinine $\mathrm{mg} / \mathrm{dL})+6.4(11)(10)$. ALBI grade demonstrated an optimal assessment method to predict the prognosis and mortality of liver function impaired which is also in advantage of treatment choice demonstrated by some recent studies. Only TB and ALB are used as covariates in the grade assessment of severity of hepatic impairment(12-14). MELD score showed positive correlation with the change of morinidazole $\mathrm{AUC}_{0-\infty}$ in our study probably due to the covariate of serum creatinine in the formula. However, the sample size was not adequate to analyze the statistical significance of the correlation. Hence a further study is needed to analyze which liver function assessment method is the best to predict the change in morinidazole PK parameters in hepatic impaired population. 

significant correlation with $\mathrm{AUC}_{0-24}$, but PT, ALB and AST had significant correlation with $\mathrm{AUC}_{0-24}$. However, ALT and AST are the markers of hepatocellular damage rather than liver function(15). A small sample size of only 3 patients with impaired probably attributed to the major renal elimination pathway of morinidazole(4). morinidazole AUC change among hepatic impaired population, but it needs further studies to validate.

A PK study of a single dose of 500mg morinidazole in healthy subjects reported impaired population showed that after administrating a single dose of morinidazole the $\mathrm{AUC}_{0-\infty}, \mathrm{CL}, \mathrm{C}_{\max }$ and $\mathrm{t}_{1 / 2}$ of controlled healthy subjects were $71.94 \pm 15.95$ $\mu \mathrm{g} \times \mathrm{h} / \mathrm{mL}, 7.21 \pm 1.64 \mathrm{~L} / \mathrm{h}, 13.74 \pm 3.14 \mu \mathrm{g} / \mathrm{mL}$ and $5.54 \pm 0.63 \mathrm{~h}$, respectively, while the $\mu \mathrm{g} \times \mathrm{h} / \mathrm{mL}, 5.21 \pm 1.47 \mathrm{~L} / \mathrm{h}, 11.65 \pm 2.97 \mu \mathrm{g} / \mathrm{mL}$ and $7.52 \pm 1.17 \mathrm{~h}$ respectively. The $\mathrm{AUC}_{0-\infty}$ 
adjustment strategy was referred to PK parameters of unchanged morinidazole, not the metabolite.

Our PPK study showed that the ratio of $\mathrm{AUC}_{0-\infty}$ of moderate hepatic impaired subjects without impaired renal function to $\mathrm{AUC}_{0-\infty}$ of healthy matched subjects was less than 2, meanwhile no SAE was reported from both groups in the PK study. Therefore, there is no need to adjust the dosage of morindazole in patients with moderate hepatic impairment and normal renal function. However, since the AEs incidence had significant difference between the two group with a higher incidence in liver function impaired group(2), safety monitoring during the administration of morinidazole was considered for the hepatic impaired group. The ratio of $\mathrm{AUC}_{0-\infty}$ of moderate hepatic impaired subjects combined with mild renal function impairment to $\mathrm{AUC}_{0-\infty}$ of healthy matched subjects was more than 2 . As a result, dosage adjustment should be considered. The PK study of morinidazole in healthy subjects showed a positively correlated relationship between dosage and $\mathrm{AUC}_{0-\mathrm{t}}$ ( $\mathrm{r}$ was 0.979) (3). Morinidazole showed a linear relationship between dosage and AUC. Morinidazole is a concentration-dependence antimicrobial agent and the PK/PD index is AUC/MIC(16). The $t_{1 / 2}$ of moderate liver function impaired subjects with mild renal function impairment was prolonged by 1.86 times than that of healthy controlled subjects. Therefore, a prolonged administration interval without dose adjustment of 500mg per day should be considered.

Dosage adjustment by both dosage and interval should also be considered among the population combined with both moderate liver function impaired and 
moderate/severe renal function impaired or both severe impaired liver function and renal function. The administration adjustment strategy requires a further study. Whether the dosage adjustment among both renal and mild liver dysfunction patients also needs further data collections from clinical practice.

Elderly always combined with physiologically decreased glomerular filtration rate(GFR). One study showed that there was $68 \%$ elderly $(73.7 \pm 6$ year) who had the creatinine clearance rate $(\mathrm{CCr})<80 \mathrm{~mL} / \mathrm{min} / 1.73 \mathrm{~m}^{2}(17)$. The other study showed there were $19.3 \%$ of elderly over 60 years old whose GFR $<60 \mathrm{~mL} / \mathrm{min} / 1.73 \mathrm{~m}^{2}$. Most of them combined with hypertension, diabetes, cardiovascular disease and renal impairment. Only $0.7 \%$ elderly had decreased GFR without other comorbidities and renal damage. Aging, hypertension and cardiovascular disease had correlation with decreased GFR(18). Since 70\% morinidazole is excreted via kidney(3), the eGFR calculation is necessary for the elderly if they also present impaired liver function.

The limitation of this study is the small sample size of moderate liver function impaired subjects with mild renal function impairment. The other limitation is that a PK study with 500mg q24h regimen of morinidazole infusion among both liver and renal impaired population was not conducted to collect the AUC data and compare with AUC of 500mg q12h of morinidazole in healthy subject.

\section{Conclusion}

The PPK model of morinidazole was validated by this study. Moderate liver function impairment and body weight were the significant covariates for CL and V, respectively. According to results of this study, it is not necessary for moderate 

adjust the morinidazole dosage. For patient with moderate hepatic and mild renal impairment, morinidazole administration should be considered as 500mg every 24 hours. If a patient has moderate/severe liver and renal function impaired, both dosage and interval adjustment of morinidazole should be considered. For patient with mild liver function and renal function impairment, an intensive safety monitoring of safety and therapeutic drug monitoring might be needed during the administration of morinidazole and dosage adjustment is required, if necessary. For elderly patients with liver function impairment, eGFR calculation is recommended before administration of morinidazole.

\section{Acknowledgments}

\section{Funding}

This study is funded by National Project for Essential Drug Research and

371 1. Gao R, Li L, Xie C, Diao X, Zhong D, Chen X. 2012. Metabolism and pharmacokinetics of morinidazole in humans: identification of diastereoisomeric morpholine N+-glucuronides catalyzed by UDP glucuronosyltransferase 1A9. Drug Metab Dispos 40:556-567. 
3. China Package Insert of Morinidazole and Sodium Chloride Injection.

4. Zhang H, Huang L, Huang YY, Yi B, Pei Q, Tan HY, Huang J, Liu JS, Yuan H, Yang GP. 2014.

5. Group KDIGOKCW. 2013. KDIGO 2012 clinical practice guideline for the evaluation and management of chronic kidney disease. Kidney International Supplements 3:150. measured creatinine clearance in recently admitted critically ill patients with normal plasma creatinine concentrations. BMC Nephrol 14:250. prevalence estimates, and better risk predictions.

9. Administration UFaD. 2003. Guidance for industry. Pharmacokinetics in patients with 
397 11. Chen B, Lin S. 2017. Albumin-bilirubin (ALBI) score at admission predicts possible outcomes in patients with acute-on-chronic liver failure. Medicine (Baltimore) 96:e7142.

12. Zhu J, Guo X, Qi X. 2017. Albumin-bilirubin, Child-Pugh, and model for end-stage liver disease scores for the assessment of prognosis in cirrhotic patients. Turk J Gastroenterol 28:533-534.

13. Xavier SA, Vilas-Boas R, Boal Carvalho P, Magalhaes JT, Marinho CM, Cotter JB. 2018.

14. Hiraoka A, Kumada T, Kudo M, Hirooka M, Tsuji K, Itobayashi E, Kariyama K, Ishikawa T, 97:133-138. 
bioRxiv preprint doi: https://doi.org/10.1101/312728; this version posted May 2, 2018. The copyright holder for this preprint (which was not certified by peer review) is the author/funder. All rights reserved. No reuse allowed without permission.

419 18. Abdulkader R, Burdmann EA, Lebrao ML, Duarte YAO, Zanetta DMT. 2017. Aging and decreased glomerular filtration rate: An elderly population-based study. 12:e0189935. 


\section{Figures}


Figure 1 Unchanged Morinidazole Plasma Concentration Data for model building
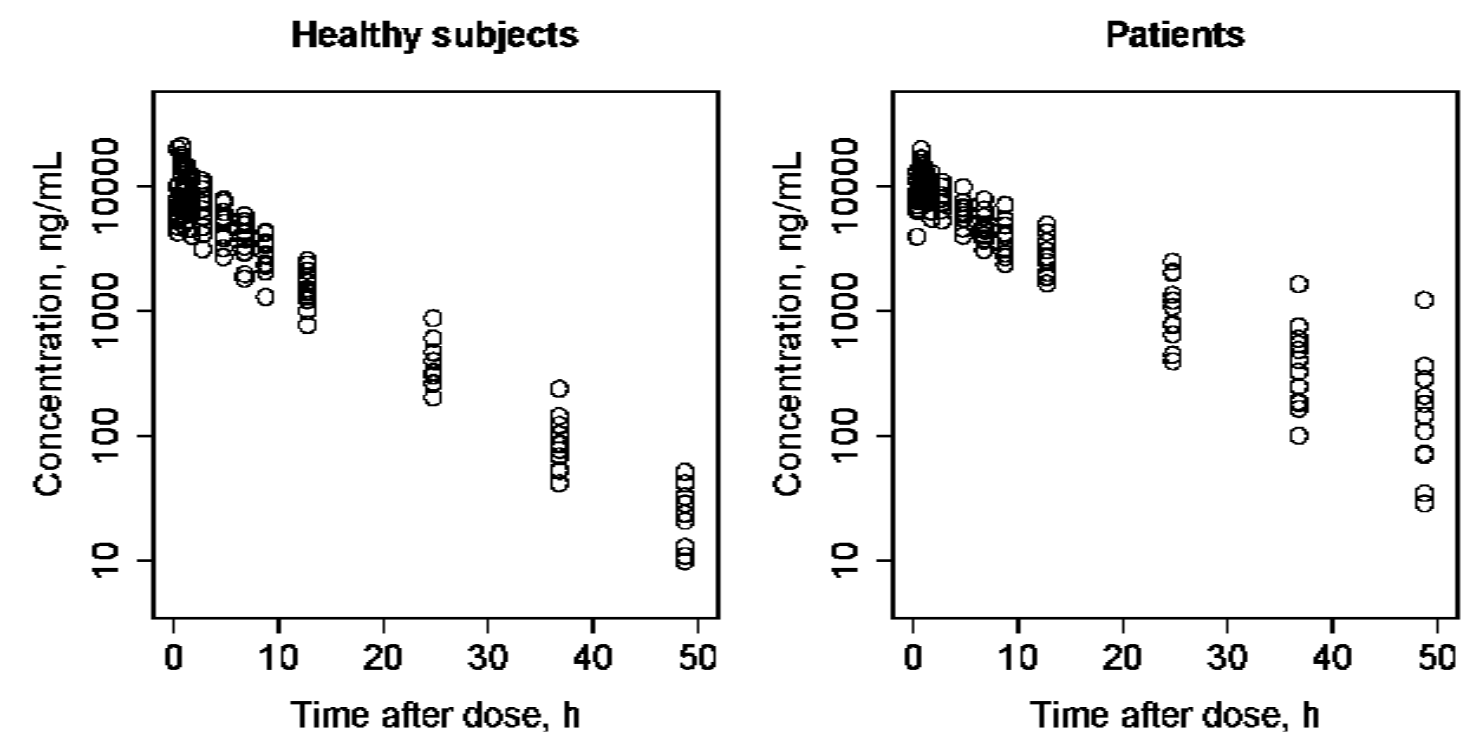


\section{Figure 2 General goodness-of-fit plots for PPK final model}
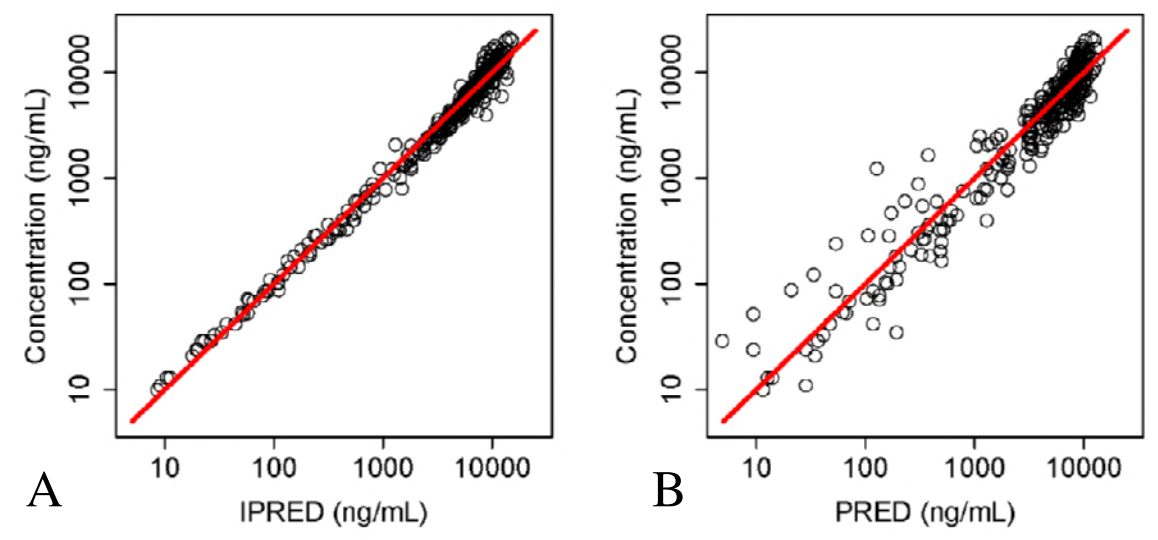

(A)Individual prediction vs. observation ;

(B) Population prediction vs. observation

(C)Conditional weighted residual vs population prediction ;

(D) Conditional weighted residual vs time ;

The red line in (A) and (B) represent regression line, respectively, whereas in (C) and (D) are the position where
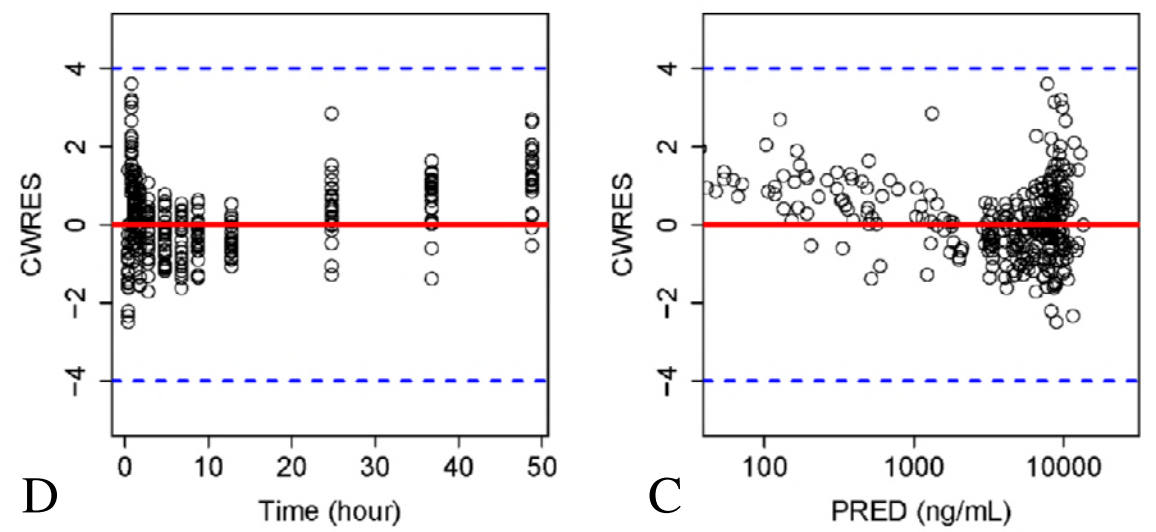


\section{Figure 3 VPC results validated the prediction ability of final model}

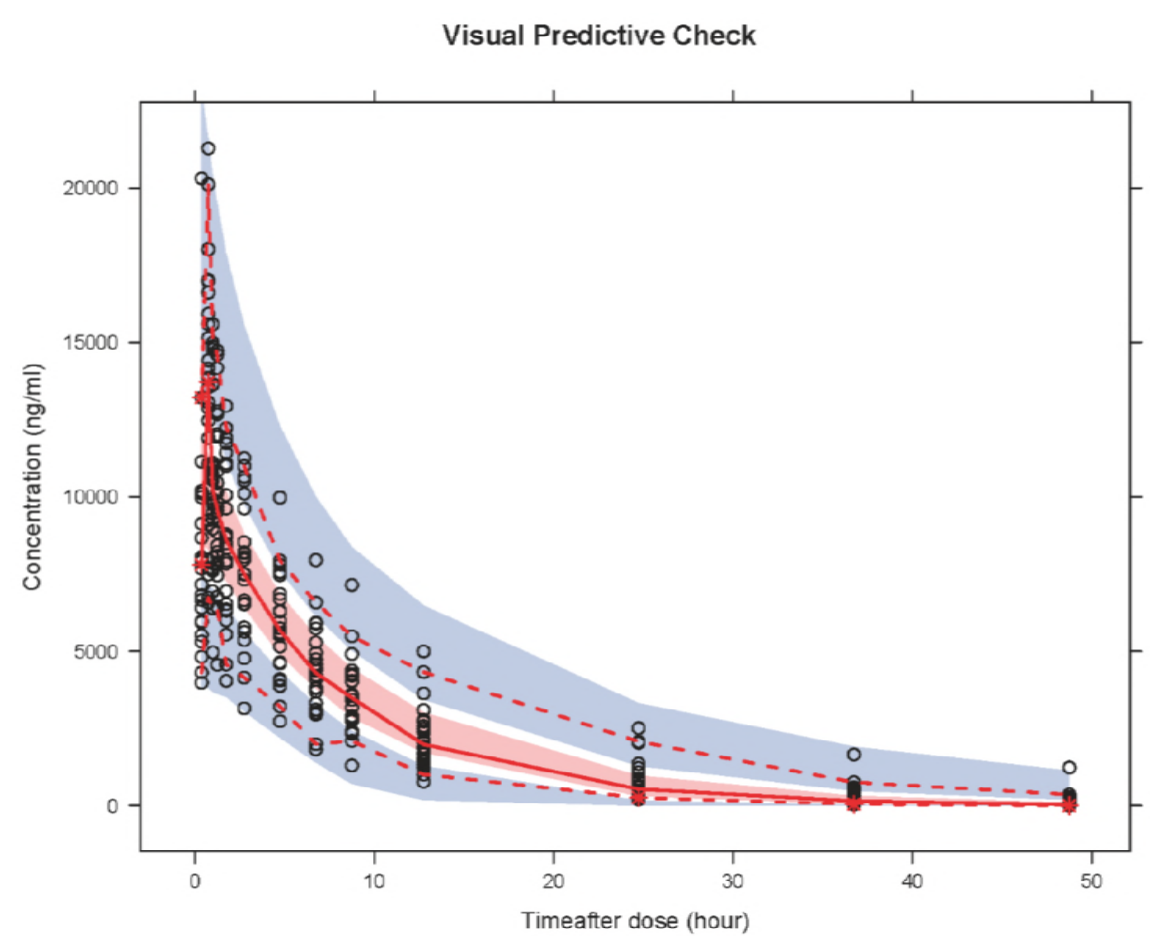

Open circles represent observed concentrations, the solid line and the dashed line represents the median and the $95 \%$ CI of observation, respectively. The middle red shadow areas represent the $95 \%$ confidence intervals of median for the results of 1000 times simulation of final model and the blue shadow areas represent the $95 \%$ confidence intervals of the 2.5 th and 97.5 th percentiles of the results of 1000 times simulation of pharmacokinetic final model. 


\section{Figure 4 the correlation between $\mathrm{AUC}_{0-24}$ and Child-Pugh score}
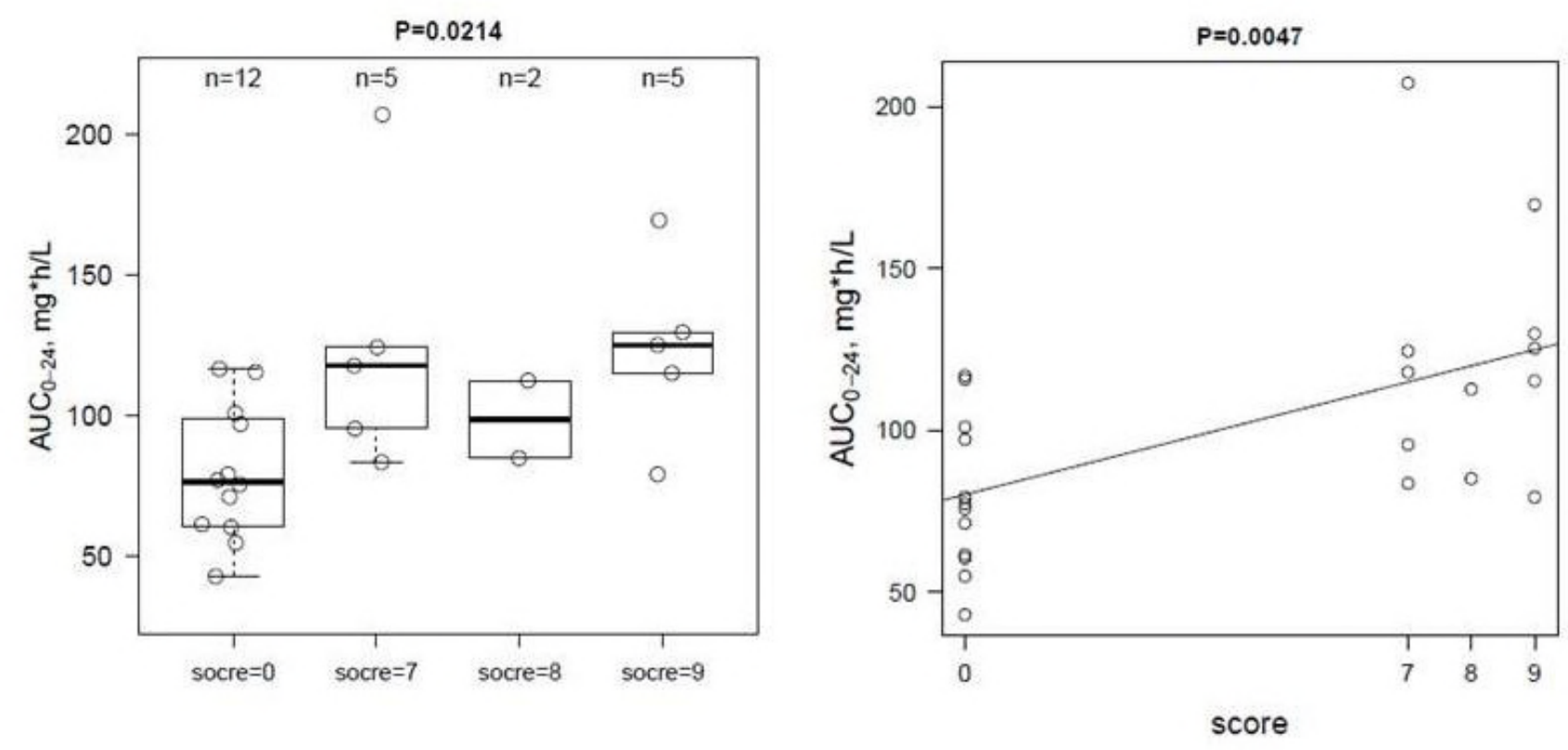

A The $\mathrm{AUC}_{0-24}$ of subjects with different Child-Pugh Score

B The linear trend of $\mathrm{AUC}_{0-24}$ of subjects with different Child-Pugh Score 
Figure 5 The linear trend of $\mathrm{AUC}_{0-\infty}$ of subjects with different MELD and Child-Pugh Score

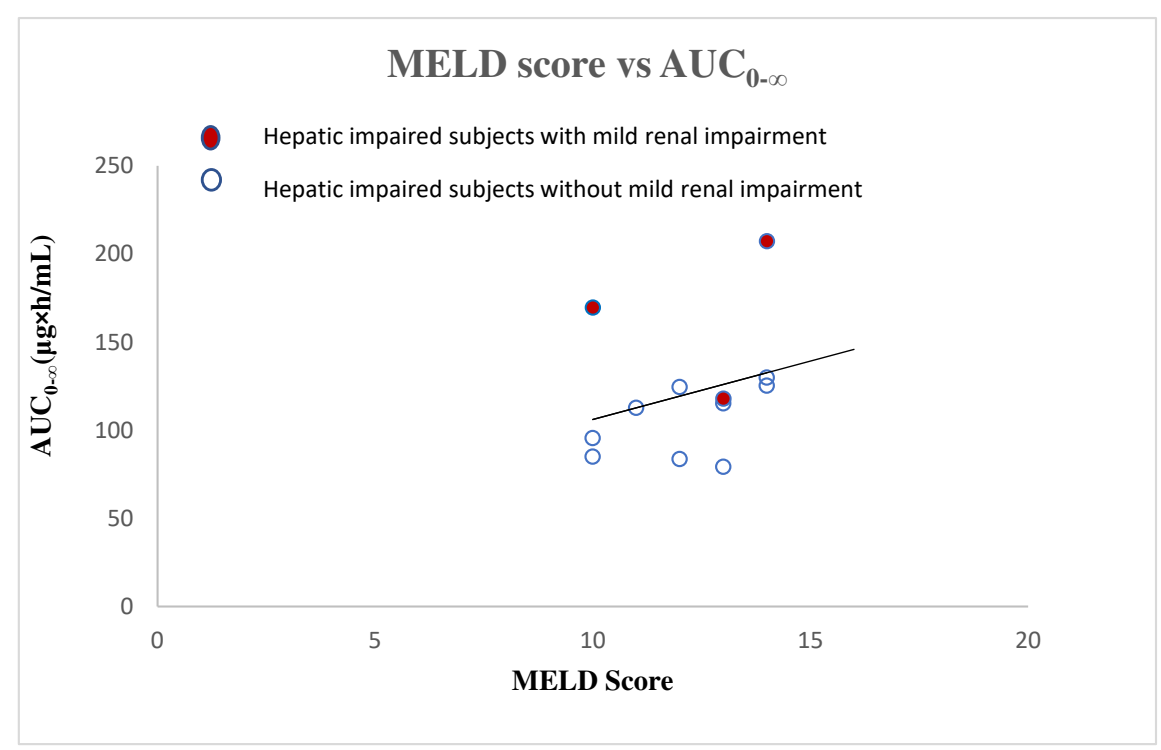

A the correlation between MELD score and $\mathrm{AUC}_{0-\infty}$ in hepatic impaired group

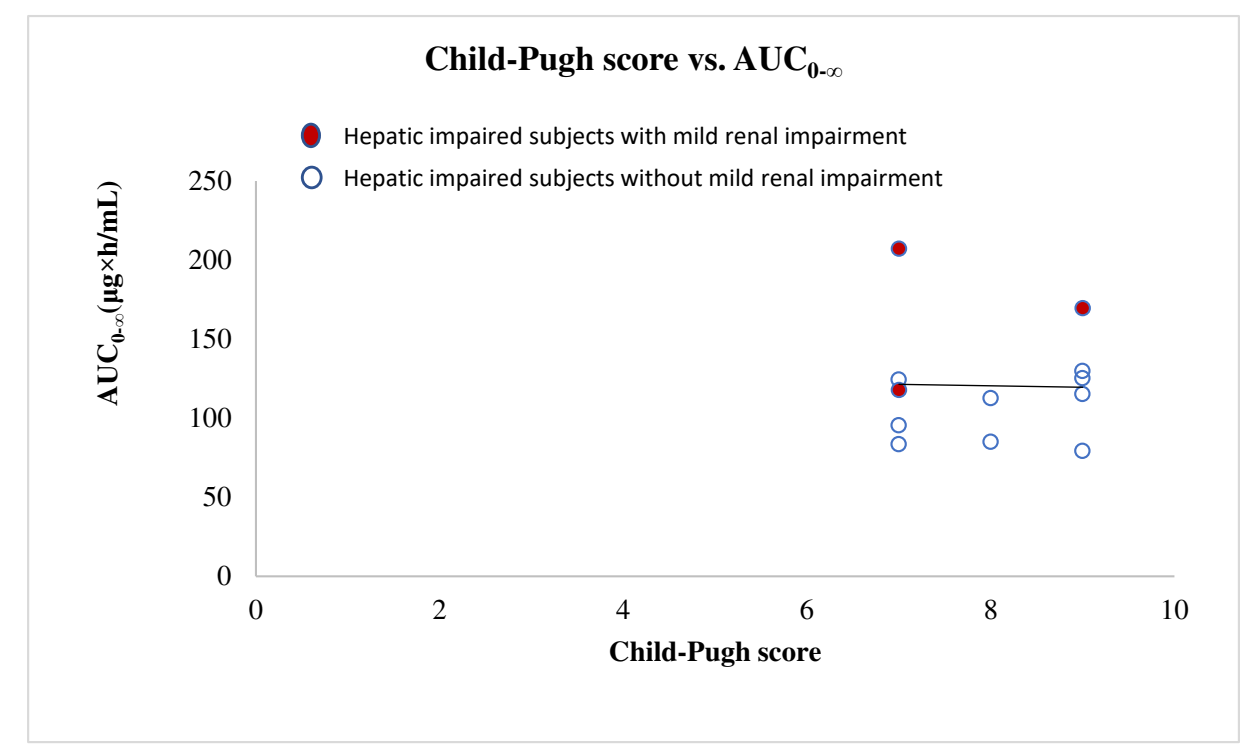

B the correlation between Child-Pugh score and $\mathrm{AUC}_{0-\infty}$ in hepatic impaired group 


\section{Tables}

Table 1 Demographic Characteristics of subjects in the PK study among moderate liver dysfunction population

\begin{tabular}{|c|c|c|c|}
\hline & $\begin{array}{l}\text { Healthy subject Group } \\
(\mathrm{N}=12)\end{array}$ & $\begin{array}{l}\text { Patient Group } \\
(\mathrm{N}=12)\end{array}$ & $\begin{array}{l}\text { Total } \\
(\mathrm{N}=\mathbf{2 4})\end{array}$ \\
\hline Gender, male (\%) & $7(58.33)$ & $7(58.33)$ & $14(58.33)$ \\
\hline Age(years) & $47.00(35.00-67.00)$ & $51.00(37.00-65.00)$ & $\begin{array}{c}48.50 \\
(35.00-67.00)\end{array}$ \\
\hline Weight(kilograms) & $60.50(47.00-78.50)$ & $66.50(44.50-92.00)$ & $\begin{array}{c}63.00 \\
(44.50-92.00)\end{array}$ \\
\hline Height(centimeters) & $\begin{array}{c}161.00 \\
(150.00-179.00)\end{array}$ & $\begin{array}{c}169.50 \\
(155.00-180.00)\end{array}$ & $\begin{array}{c}165.50 \\
(150.00-180.00)\end{array}$ \\
\hline $\operatorname{BMI}\left(\mathrm{kg} / \mathrm{m}^{2}\right)$ & $23.98(19.27-27.82)$ & $23.61(17.83-28.40)$ & $\begin{array}{c}23.72 \\
(17.83-28.40)\end{array}$ \\
\hline \multicolumn{4}{|l|}{ Hepatic Function } \\
\hline ALT(U/L) & $16.00(11.00-53.00)$ & $40.00(22.00-89.00)$ & $\begin{array}{c}23.50 \\
(11.00-89.00)\end{array}$ \\
\hline $\mathrm{AST}(\mathrm{U} / \mathrm{L})$ & $20.50(12.00-28.00)$ & $\begin{array}{c}59.50 \\
(24.00-175.00)\end{array}$ & $\begin{array}{c}27.50 \\
(12.00-175.00)\end{array}$ \\
\hline \multicolumn{4}{|l|}{ Child-Pugh } \\
\hline \multicolumn{4}{|l|}{ Score, n (\%) } \\
\hline Normal & $12(100.00)$ & 0 & $12(50.00)$ \\
\hline 7 & 0 & $5(41.67)$ & $5(20.83)$ \\
\hline 8 & 0 & $2(16.67)$ & $2(8.33)$ \\
\hline 9 & 0 & $5(41.67)$ & $5(20.83)$ \\
\hline \multicolumn{4}{|l|}{ Renal Function } \\
\hline $\mathrm{Cr}(\mu \mathrm{mol} / \mathrm{L})$ & $62.00(45.00-85.00)$ & $\begin{array}{c}61.50 \\
(36.00-101.00)\end{array}$ & $\begin{array}{c}61.50 \\
(36.00-101.00)\end{array}$ \\
\hline $\mathrm{eGFR}\left(\mathrm{ml} / \mathrm{min} / 1.73 \mathrm{~m}^{2}\right)$ & $\begin{array}{c}105.00 \\
(90.00-120.00)\end{array}$ & $\begin{array}{c}106.50 \\
(70.00-122.00)\end{array}$ & $\begin{array}{c}105.00 \\
(70.00-122.00)\end{array}$ \\
\hline \multicolumn{4}{|c|}{ Concomitant Medication, } \\
\hline antiviral agent, $\mathrm{n}(\%)$ & 0 & $12(100)$ & $12(50)$ \\
\hline
\end{tabular}

BMI: body mass index; ALT: alanine aminotransferase; AST: aspartate transaminase;

Cr: creatinine; eGFR: estimated glomerular filtration rate 
Table 2 the result of PK parameters by 1000 bootstrap via final model

\begin{tabular}{lcc}
\hline & Estimate(RSE\%) & 1000 successful bootstrap median $(95 \% \mathrm{CI})$ \\
\hline PK Parameter & & \\
\hline CL $(\mathrm{L} / \mathrm{h})$ & $4.32(8.30)$ & $4.32(3.64-5.13)$ \\
\hline V $(\mathrm{L})$ & $55.5(4.80)$ & $55.4(50.8-60.8)$ \\
\hline OCL_pat & $0.521(35.5)$ & $0.524(0.185-0.943)$ \\
\hline Interindividual variability & $27.2(18.3-34.8)$ \\
\hline CL, \% & $28.9(13.6)$ & $20.5(11.5-28.1)$ \\
\hline V, \% & $21.3(19.9)$ & \\
\hline Residual error & & $21.9(19.8-24.2)$ \\
\hline Prop, \% & $21.8(4.80)$ & \\
\hline
\end{tabular}

CI: Confidential interval 
Table 3 Descriptive Analysis of Individuals PK Parameters by Different Groups

\begin{tabular}{|c|c|c|c|c|c|c|}
\hline $\begin{array}{l}\text { PK } \\
\text { Parameters }\end{array}$ & $\begin{array}{l}\text { Subjects of } \\
\text { moderate liver } \\
\text { function } \\
\text { impaired } \\
\text { combined with } \\
\text { renal function } \\
\text { imparied } \\
\mathrm{N}=3\end{array}$ & $\begin{array}{l}\text { The matched } \\
\text { healthy } \\
\text { subjects } \\
\mathrm{N}=3\end{array}$ & $\begin{array}{l}\text { Subjects of } \\
\text { moderate } \\
\text { liver function } \\
\text { impaired with } \\
\text { normal renal } \\
\text { function } N=9\end{array}$ & $\begin{array}{l}\text { The matched } \\
\text { healthy } \\
\text { subjects } \\
\mathrm{N}=9\end{array}$ & $\begin{array}{l}\text { Subjects of } \\
\text { moderate } \\
\text { liver function } \\
\text { impaired } \\
\mathrm{N}=12\end{array}$ & $\begin{array}{l}\text { The matched } \\
\text { healthy } \\
\text { subjects } \\
\mathrm{N}=12\end{array}$ \\
\hline \multicolumn{7}{|l|}{ CL (L/h) } \\
\hline Mean \pm SD, & $3.20 \pm 0.94$ & $6.89 \pm 2.09$ & $4.89 \pm 0.97$ & $6.85 \pm 2.31$ & $4.47 \pm 1.19$ & $6.86 \pm 2.17$ \\
\hline (Range) & $(2.41-4.24)$ & $(4.95-4.16)$ & $(3.85-6.31)$ & $(4.28-11.64)$ & $(2.41-6.31)$ & $(4.28-11.64)$ \\
\hline СI90\% & $1.62-4.78$ & $3.36-10.42$ & $4.30-5.49$ & $5.41-8.28$ & $3.85-5.09$ & $5.73-7.98$ \\
\hline \multicolumn{7}{|l|}{ V (L) } \\
\hline Mean \pm SD, & $44.65 \pm 7.90$ & $54.04 \pm 19.98$ & $52.05 \pm 8.51$ & $54.20 \pm 19.11$ & $50.20 \pm 8.67$ & $54.16 \pm 18.39$ \\
\hline (Range) & $(35.53-49.30)$ & $(39.04-76.72)$ & $(40.20-66.1)$ & $(31.68-88.02)$ & $(35.53-66.09)$ & $(31.68-88.02)$ \\
\hline CI90\% & $31.33-57.98$ & $20.36-87.73$ & $46.77-57.32$ & $42.35-66.05$ & $45.70-54.69$ & $44.62-63.69$ \\
\hline \multicolumn{7}{|l|}{$\mathrm{C}_{\max }(\mathrm{mg} / \mathrm{L})$} \\
\hline Mean \pm SD, & $16.53 \pm 3.62$ & $12.13 \pm 4.61$ & $13.38 \pm 2.39$ & $13.05 \pm 5.18$ & $14.17 \pm 2.93$ & $12.82 \pm 4.85$ \\
\hline (Range) & $(12.87-20.11)$ & $(6.82-15.15)$ & $(9.24-17.01)$ & $(6.94-21.28)$ & $(9.24-20.11)$ & $(6.82-21.28)$ \\
\hline СІ90\% & $10.42-22.63$ & $4.36-19.90$ & $11.90-14.86$ & $9.85-16.26$ & $12.65-15.69$ & $10.30-15.34$ \\
\hline \multicolumn{7}{|l|}{$\mathbf{t}_{1 / 2}(\mathrm{~h})$} \\
\hline Mean \pm SD, & $10.18 \pm 3.45$ & $5.39 \pm 0.49$ & $7.55 \pm 1.58$ & $5.48 \pm 0.59$ & $8.21 \pm 2.32$ & $5.45 \pm 0.55$ \\
\hline (Range) & $(8.03-14.16)$ & $(4.86-5.83)$ & $(5.37-10.23)$ & $(4.67-6.18)$ & $(5.37-14.16)$ & $(4.67-6.18)$ \\
\hline CI90\% & $4.36-15.99$ & $4.56-6.21$ & $6.27-8.53$ & $5.11-5.84$ & $7.00-9.41$ & $5.17-5.74$ \\
\hline
\end{tabular}




\begin{tabular}{|c|c|c|c|c|c|c|}
\hline \multicolumn{7}{|l|}{$(\mu g \times \mathbf{h} / \mathbf{m L})$} \\
\hline Mean \pm SD, & $164.91 \pm 44.84$ & $77.18 \pm 23.09$ & $105.62 \pm 19.92$ & $80.22 \pm 25.24$ & $120.44 \pm 37.05$ & $79.46 \pm 23.71$ \\
\hline (Range) & $(117.90-207.20)$ & $(54.87-100.98)$ & $(79.25-129.78)$ & $(42.94-116.75)$ & $(79.25-207.20)$ & $(42.94-116.75)$ \\
\hline CI90\% & $89.32-240.50$ & $38.24-116.11$ & $93.28-117.97$ & $64.58-95.87$ & $101.24-139.65$ & $67.17-91.75$ \\
\hline \multicolumn{7}{|l|}{$\mathrm{C}_{24 h}(\mathrm{ug} / \mathrm{ml})$} \\
\hline Mean \pm SD, & $2.11 \pm 0.94$ & $0.45 \pm 0.14$ & $1.06 \pm 0.43$ & $0.48 \pm 0.18$ & $1.32 \pm 0.72$ & $0.47 \pm 0.17$ \\
\hline (Range) & $(1.28-3.13)$ & $(0.35-0.61)$ & $(0.56-1.67)$ & $(0.24-0.86)$ & $(0.56-3.13)$ & $(0.24-0.86)$ \\
\hline CI90\% & $0.527-3.697$ & $0.207-0.687$ & $0.797-1.328$ & $0.37-0.60$ & $0.951-1.698$ & $0.385-0.561$ \\
\hline \multicolumn{7}{|l|}{$\mathrm{AUC}_{0-24}$} \\
\hline \multicolumn{7}{|l|}{$(\mu g \times h / m L)$} \\
\hline Mean \pm SD, & $130.90 \pm 24.18$ & $73.69 \pm 22.24$ & $93.23 \pm 14.47$ & $76.34 \pm 24.14$ & $102.65 \pm 23.43$ & $75.68 \pm 22.70$ \\
\hline (Range) & (103.04-146.47) & $(51.70-96.17)$ & $(74.05-109.34)$ & $(41.15-112.20)$ & $(74.05-146.47)$ & $(41.15-112.20)$ \\
\hline СI90\% & $90.14-171.67$ & $36.20-111.18$ & $84.26-102.20$ & $61.38-91.30$ & $90.50-114.79$ & $63.91-87.45$ \\
\hline
\end{tabular}


Table 4 MELD score and ALBI score of subjects in hepatic impaired group

\begin{tabular}{|c|c|c|c|c|c|c|}
\hline No. & Child-Pugh & MELD & ALBI & ALBI & $\mathrm{eGFR}(\mathrm{ml} / \mathrm{mi}$ & $\mathrm{AUC}_{0-\infty}$ \\
\hline & score & score & score & grade & $\mathrm{n} / 1.73 \mathrm{~m} 2)$ & $(\mu \mathrm{g} \times \mathrm{h} / \mathrm{mL})$ \\
\hline 1 & 9 & 10 & -1.36449 & 3 & 90 & 169.618 \\
\hline 2 & 9 & 13 & -1.98412 & 2 & 100 & 79.25437 \\
\hline 3 & 8 & 10 & -2.26514 & 2 & 121 & 85.0051 \\
\hline 4 & 7 & 13 & -1.3875 & 3 & 72 & 117.8995 \\
\hline 5 & 9 & 13 & -1.93767 & 2 & 102 & 115.2206 \\
\hline 6 & 7 & 14 & -1.69243 & 2 & 70 & 207.2024 \\
\hline 7 & 9 & 14 & -1.92343 & 2 & 96 & 129.7757 \\
\hline 8 & 7 & 12 & -1.9492 & 2 & 111 & 124.4122 \\
\hline 9 & 7 & 12 & -1.88932 & 2 & 120 & 83.55615 \\
\hline 10 & 7 & 10 & -1.48837 & 2 & 119 & 95.50186 \\
\hline 11 & 8 & 11 & -1.79168 & 2 & 112 & 112.6202 \\
\hline 12 & 9 & 14 & -1.67024 & 2 & 122 & 125.2662 \\
\hline
\end{tabular}

